UDC 347.45 .47

LBC 47.404 .2

\title{
THE EFFECTIVENESS OF PROCUREMENT AS A KEY GOAL OF THE RUSSIAN CONTRACT SYSTEM
}

\author{
Marina V. Shmeleva \\ Saratov State Academy of Law, Saratov, Russian Federation
}

\begin{abstract}
Introduction: the article is devoted to the issues of improving the effectiveness of public procurement. Public procurement can now be used by the state to achieve a variety of benefits that go beyond the mere acquisition of goods, works or services. Such advantages can be manifested not only in the implementation of cost-effective procurement procedures, but also in obtaining the public benefits of environmental or social character. For that purpose, the author reveals the importance of the problem of effectiveness of procurement procedures for the Russian system of public procurement. With the help of methods of scientific cognition, first of all, the dialectical method, the system of public procurement in interrelation and development was considered. The paper also uses the specific methods of scientific knowledge, including: system and structural, formal and logical, as well as special and legal methods of normative interpretation and comparative law. Results: it is pointed out that there are a number of public procurement objectives that can be identified and that pursue some or even most public procurement systems. These goals are realized through a variety of means and regulatory rules on conducting the public procurement procedures, which are one of these tools. When working out, implementing and interpreting the regulations, it is essential to understand these possible objectives and how they relate to each other - and, of course, to understand their relevance to a particular procurement system. One of the main and first objectives of most procurement systems is the successful acquisition of goods, works or services, in other words, the effectiveness of procurement procedures. The article reveals the value of the purpose of the effective procurement procedures for the Russian system of public procurement. Conclusions: according to the results of the study it should be assumed that the timely and full meeting the customers needs in goods, works, and services with the necessary price, quality and reliability is an important goal of the public sector. At the same time, the state is interested in the fact that as a result of procurement, not only goods (works and services) are purchased at a low price, but also the social and economic efficiency is achieved.

Key words: public procurement, contract system, social and economic efficiency, objectives of public procurement, object of procurement, value of public procurement, public customer, procurement procedures, methods of determining the contractor (supplier), conclusion of public contract, procurement legislation.
\end{abstract}

УДК 347.45 .47

ББК 47.404 .2

\section{ЭФФЕКТИВНОСТЬ ОСУЩЕСТВЛЕНИЯ ЗАКУПОК КАК ВАЖНЕЙШАЯ ЦЕЛЬ РОССИЙСКОЙ КОНТРАКТНОЙ СИСТЕМЫ}

\author{
Марина Владимировна Шмелева \\ Саратовская государственная юридическая академия, г. Саратов, Российская Федерация
}




\section{ТЕОРИЯ И ПРАКТИКА ГОСУДАРСТВЕННО-ПРАВОВОГО РАЗВИТИЯ}

ваны также частные методы научного познания, в том числе: системно-структурный, формально-логический, а также специально-юридические методы нормативного толкования и сравнительного правоведения. Результаты: указывается на то, что существует целый ряд целей государственных закупок, которые могут быть идентифицированы и которые преследуются некоторыми или даже большинством систем государственных закупок. Эти цели реализуются с помощью различных средств, а также нормативных правил по проведению процедур государственных закупок, которые являются одними из этих средств. При разработке, применении и толковании нормативных правил крайне важно понимать эти возможные цели, а также понимать, каким образом они связаны друг с другом - и, конечно же, понимать их значимость для конкретной системы закупок. Одна из главных и первых задач большинства систем закупок - это успешное приобретение товаров, работ или услуг, другими словами - эффективность проведения закупочных процедур. В статье раскрыто значение цели эффективности проведения закупочных процедур для российской системы государственных закупок. Выводы: по результатам проведенного исследования следует полагать, что своевременное и полное удовлетворение потребностей заказчиков в товарах, работах и услугах с необходимыми показателями цены, качества и надежности выступает важной целью государственного сектора экономики. При этом государство заинтересовано в том, чтобы в результате проведения закупок не только закупались товары (работы, услуги) по низкой цене, но и достигалась социальная и экономическая эффективность.

Ключевые слова: государственные закупки, контрактная система, социальная и экономическая эффективность, цели государственных закупок, объект закупки, значение государственных закупок, государственный заказчик, закупочные процедуры, способы определения исполнителя (поставщика, подрядчика), заключение государственного контракта, законодательство о закупках.

\section{Введение}

Существует целый ряд целей государственных закупок, которые могут быть идентифицированы и которые преследуются некоторыми или даже большинством систем государственных закупок. Эти цели реализуются с помощью различных средств, а также нормативных правил по проведению процедур государственных закупок, которые являются одним из этих средств. При разработке, применении и толковании нормативных правил крайне важно понимать эти возможные цели, а также понимать, каким образом они связаны друг с другом - и, конечно же, понимать их значимость для конкретной системы закупок.

Обобщая опыт различных подходов к трактовке целей государственных закупок, можно выделить восемь основных целей системы государственных закупок: 1) создание условий для своевременного и полного удовлетворения потребностей юридических лиц (заказчиков) в товарах, работах и услугах с необходимыми показателями цены, качества и надежности (эффективность закупок); 2) развитие добросовестной конкуренции; 3) эффективная реализация социальных, промышленных и экологических целей («горизонтальной политики») в области закупок; 4) расширение возможностей участия юридических и физических лиц в закупке товаров, работ и услуг для нужд заказчиков и стимулирование такого участия; 5) предотвращение коррупции и других злоупотреблений; 6) подотчетность; 7) импортозамещение и поддержка отечественных производителей; 8) открытие рынка для международной торговли.

Одна из главных и первых задач большинства систем закупок - это успешное приобретение товаров, работ или услуг, другими словами, эффективность проведения закупочных процедур. Заказчики обеспокоены необходимостью осуществить закупку на наилучших возможных условиях. В литературе это называют соотношением цены и качества $[2$, p. 220], в качестве эффективности или экономической эффективности $[4$, p. 390$]$.

\section{Эффекти вность в государственных закупках}

По мнению О. Декел, категория эффективности в качестве одного из смыслов успешной закупки означает не только выгоду при приобретении товаров, работ или услуг, но и общие экономические выгоды для общества при эффективном распределении ресурсов [3, p. 37].

Таким образом, как представляется, государственные закупки могут быть использованы государством для достижения различных преимуществ, которые выходят за рамки простого приобретения товаров, работ или услуг. 
К примеру, такие преимущества могут носить социальный или экологический характер в форме создания доступной среды или рабочих мест для граждан с ограниченными возможностями. Так, в 2015 г. была утверждена Федеральная целевая программа «Доступная среда» ${ }^{1}$, основной задачей которой было обеспечение равного доступа инвалидов к приоритетным объектам и услугам в приоритетных сферах жизнедеятельности инвалидов и других маломобильных групп населения.

Далее представляется необходимым обратиться к сущности исследуемой цели закупок, которая, на наш взгляд, может иметь три аспекта:

1) обеспечение соответствия приобретаемых товаров, работ или услуг заявленным требованиям. По мнению ряда зарубежных авторов, обеспечение соответствия приобретаемых для государства товаров (работ и услуг) означает то, что они отвечают требованиям для выполнения определенной государственной задачи и то, что они не переоценены, другими словами, не являются «позолоченными» $[1$, p. 6];

2) заключение договора на лучших возможных условиях (что не обязательно означает самую низкую цену);

3) обеспечение гарантии того, что участник закупки будет в состоянии обеспечить исполнение условий контракта.

В методологическом плане мы полагаем важным обратить внимание на то, что в определенной степени политика и инструменты, которые обеспечивают достижение цели эффективности закупочных процедур, такие как конкурентные процедуры, заключение контракта и прозрачность закупок, те же самые, что и политика и инструменты, которые направлены на исполнение других целей государственных закупок. Поэтому можно говорить о существовании неразрывной связи между всеми целями государственных закупок.

\section{Юридические конфликты между целями системы государственных закупок и пути решения таких конфликтов}

Не отрицая продуктивности такого подхода к исследованию целей государственных закупок, все же полагаем для решения постав- ленных в настоящей работе вопросов не преувеличивать положительное значение связи между целями института государственных закупок, поскольку такая связь не всегда способствует реализации всех целей системы закупок. Так, существуют определенные ситуации, в которых достижение цели своевременного и полного удовлетворения потребностей юридических лиц (заказчиков) в товарах, работах и услугах, особенно если фокусироваться на конкретной закупке, может вступить в противоречие с достижением других целей контрактной системы, и тогда требуется нахождение определенного баланса между этими целями.

В качестве конкретного примера может служить случай, когда заказчик принимает предложение, которое не соответствует некоторым формальным требованиям закупочной документации - например, заявка на участие поздно подана или не содержит залога в требуемой форме. В этом случае принцип равного обращения может свидетельствовать о том, что заявка должна быть отклонена. Однако если заявка является лучшим предложением по цене, то она должна быть принята, поскольку это обеспечит лучшее соотношение цены и качества для заказчика ${ }^{2}$ [3].

Другой потенциальной областью конфликта с целью эффективной закупки выступает цель по предотвращению коррупции. Нормативные правила, направленные на реализацию цели предотвращения коррупции, призваны снизить уровень коррупции при проведении закупочных процедур за счет ограничения возможностей для злоупотреблений со стороны заказчика в пользу конкретного участника закупки, в то же время они же одновременно ограничивают возможности для заказчиков по использованию определенных способов закупки для получения лучшего предложения в конкретной закупке.

В целях настоящего исследования, как мы полагаем, важно рассмотреть вопрос о том, как решить юридические конфликты, возникающие между целями государственных закупок при стремлении заказчика достичь лучшего соотношения цены и качества объекта закупки. Показателен в данном отношении пример, когда конфликт возникает между действиями заказчика, которые позволяют дос- 


\section{ТЕОРИЯ И ПРАКТИКА ГОСУДАРСТВЕННО-ПРАВОВОГО РАЗВИТИЯ}

тичь соотношения цены и качества в краткосрочной перспективе, и теми его действиями, которые основаны на принципах, призванных содействовать достижению соотношения цены и качества закупок в долгосрочной перспективе путем стимулирования участия поставщиков в публичной закупке. Так принцип равного обращения может работать для поддержки целей государственных закупок, в том числе цели эффективной закупки, поддерживая такое доверие между участниками закупок, которое будет побуждать их к участию в закупочных процедурах в будущем и, тем самым, будет способствовать конкуренции между ними и подаче лучшего предложения.

Таким образом, в случае примера подачи заявки с нарушением срока, упомянутого выше, отказ от принятия такой заявки будет рассматриваться как обеспечение гарантии прав участников закупок на равное обращение. Кроме того, поощрение участия в закупочных процедурах заинтересованных лиц можно рассматривать не только как поддержку принципа равного обращения, но и как поддержку цели соотношения цены и качества объекта закупки в контрактной системе в целом, а не при проведении отдельной закупки. В этом случае конфликт можно увидеть между краткосрочной целью достижения соотношения цены и качества объекта закупки (значения для конкретной закупочной процедуры) и долгосрочной целью эффективной закупки в контрактной системе в целом [1, p. 7].

\section{Выводы}

Подводя итог нашим рассуждениям, отметим, что государство заинтересовано в том, чтобы в результате проведения закупок не только закупались товары (работы, услуги) по низкой цене, но и достигалась социальная и экономическая эффективность. Эффективность, в свою очередь, как представляется, можно рассматривать в трех аспектах: 1) обеспечение соответствия приобретаемых товаров, работ или услуг заявленным требованиям; 2) заключение договора на лучших возможных условиях (что не обязательно означает самую низкую цену); 3) обеспечение гарантии того, что участник закупки будет в состоянии обеспечить поставку товаров, выполнение работ или оказание услуг на согласованных в контракте условиях.

Своевременное и полное удовлетворение потребностей заказчиков в товарах, работах, услугах с необходимыми показателями цены, качества и надежности, безусловно, выступает важной целью как частного, так и государственного сектора экономики.

Тем не менее существуют определенные различия как в вопросе получения денежных средств, так и в инструментах, используемых при осуществлении закупок. Вопервых, зачастую получение денежных средств на приобретение товаров, работ или услуг выступает более серьезной проблемой для государственного сектора, чем для частного сектора. Во-вторых, в государственном секторе существует большая тенденция к неэффективности работы специалистов по закупкам, которая проявляется в незаинтересованности должностных лиц, ответственных за организацию и проведение закупочных процедур, в результатах закупки. Такая тенденция может быть причиной того, что, к примеру, государственные организации вряд ли могут обанкротиться, и поэтому специалисты по закупкам, как правило, имеют меньше шансов быть уволенными [4, p. 77-83]. В-третьих, юридически обязательные правила выступают одним из ключевых инструментов, используемых в государственных закупках. Как следствие, существует сильная зависимость государственных закупок от формальных закупочных процедур, что в свою очередь также отличает государственные закупки от частных, которые нацелены на результат, а не на формальное соблюдение процедурных правил.

Продолжая мысль, отметим, что анализируя данные мониторинга системы закупок, проводимого Минэкономразвития России, в котором ключевыми показателями выступают количество размещенных извещений, количество проведенных закупочных процедур, количество поданных от участков закупок заявок, доля закупок у единственного поставщика ${ }^{3}$, а также составы административных правонарушений в области государственных закупок, которые носят исключительно процедурный характер, можно прийти к выводу, 
М.В. Шмелева. Эффективность осуществления закупок как цель российской контрактной системы

что государственные заказчики в большинстве случаев ориентированы больше не на закупку качественных товаров (работ, услуг) по низкой цене, а на соблюдене правил.

\section{ПРИМЕЧАНИЯ}

1 Постановление Правительства РФ от 1 дек. 2015 г. № 1297 «Об утверждении государственной программы Российской Федерации “Доступная среда” на 2011-2020 гг.» (в ред. от 21 июля 2017 г.) // Собрание законодательства РФ. - 2015. - № 49. ст. $6987 ; 2017$. - № 31 (ч. 2). - ст. 4920.

2 Такого рода случай обсуждается далее О. Декелом.

3 Доклад о результатах мониторинга применения Федерального закона «О контрактной системе в сфере закупок товаров, работ, услуг для обеспечения государственных и муниципальных нужд» от 5 апр. 2013 г. № 44-Ф3 по итогам І квартала 2017 года.

\section{СПИСОК ЛИТЕРАТУРЫ}

1. Arrowsmith, S. Public procurement regulation: an introduction / S. Arrowsmith, S. Treumer, J. Fejø, L. Jiang // University of Nottingham. - 204 p.
2. Arrowsmith, S. Regulating Public Procurement: National and International Perspectives / S. Arrowsmith, J. Linarelli, D. Wallace. - Dordrecht : Kluwer Law International, 2000. $-856 \mathrm{p}$.

3. Dekel, O. The Legal Theory of Competitive Bidding for Government Contracts / O. Dekel // Public Contract Law Journal. - 2008. - № 37. - P. 237.

4. Trepte, P. Regulating Procurement: Understanding the Ends and Means of Public Procurement Regulation / P. Trepte. - New York : Oxford university press, 2004. $-411 \mathrm{p}$.

\section{REFERENCES}

1. Arrowsmith S., Treumer S., Fejw J., Jiang L. Public procurement regulation: an introduction. University of Nottingham, 2010. 204 p.

2. Arrowsmith S., Linarelli J., Wallace D. Regulating Public Procurement: National and International Perspectives. Dordrecht, Kluwer Law International, 2000. $856 \mathrm{p}$.

3. Dekel O. The Legal Theory of Competitive Bidding for Government Contracts. Public Contract Law Journal, 2008, no. 37, p. 237.

4. Trepte P. Regulating Procurement: Understanding the Ends and Means of Public Procurement Regulation. New York, Oxford university press, 2004. $411 \mathrm{p}$.

\section{Information about the Author}

Marina V. Shmeleva, Candidate of Juridical Sciences, Associate Professor, Department of Civil Law, Saratov State Academy of Law, Volskaya St., 1, 410056 Saratov, Russian Federation, civil2012@mail.ru.

\section{Информация об авторе}

Марина Владимировна Шмелева, кандидат юридических наук, доцент кафедры гражданского права, Саратовская государственная юридическая академия, ул. Вольская, 1, 410056 г. Саратов, Российская Федерация, civi12012@mail.ru. 